\title{
EL RACISMO DEL CUERPO A LA LUZ DE LOS APORTES DE LA SOCIOLOGÍA FIGURACIONAL DE NORBERT ELIAS
}

\author{
Ezequiel Szapu iD1
}

\section{Resumen}

El presente artículo retoma los aportes de la sociología figuracional de Norbert Elias para profundizar respecto a la idea de racismo del cuerpo, elaborada con el propósito de acercarnos al abordaje de los procesos de estigmatización que involucran de manera significativa la corporalidad de las y los jóvenes. El objetivo del estudio que enmarca este trabajo es comprender los sentidos que las y los estudiantes construyen sobre los cuerpos y las emociones y establecer su vinculación con la producción de las violencias en escuelas secundarias urbanas periféricas de La Plata. Para la realización de la investigación socioeducativa se optó por un enfoque cualitativo con un diseño exploratorio. La recolección de datos se realizó mediante entrevistas en profundidad realizadas a 40 estudiantes de dos instituciones a las que asiste una población con características socioeconómicas y culturales de vulnerabilidad. El análisis de los datos se realizó según la teoría fundamentada de Glaser y Strauss. A partir de los testimonios obtenidos puede sostenerse que el rostro y el color de piel, son cualidades físicas que operan como signo de distinción y diferenciación entre sujetos y grupos. Ciertos rasgos faciales así como determinadas tonalidades de piel son consideradas inferiores, asignándole a sus portadores toda otra serie de características negativas en un proceso de generalización y esencialización que denominamos racismo del cuerpo. Quienes son objeto de estos procesos de etiquetamiento, experimentan emotividades signadas por la vergüenza, la ira, el asco y el miedo a sentirse excluidos que producen un dolor social difícil de suprimir.

Palabras clave: Racismo; Jóvenes; Cuerpos; Emociones.

\section{O RACISMO DO CORPO À LUZ DAS CONTRIBUIÇÕES DA SOCIOLOGIA FIGURACIONAL DE NORBERT ELIAS}

\section{Resumo}

Este artigo retoma as contribuições da sociologia figurativa de Norbert Elias para o aprofundamento da ideia de racismo do corpo, elaborada com o objetivo de analisar a abordagem dos processos de estigmatização que envolvem significativamente a corporalidade dos jovens. O objetivo do estudo que enquadra este trabalho é compreender os sentidos que os alunos constroem sobre corpos e emoções e estabelecer seu vínculo com a produção da violência

${ }^{1}$ Doctor en Educación por la Universidad de Buenos Aires. Licenciado y Profesor en Ciencias de la Educación por la Universidad de Buenos Aires (UBA). Becario posdoctoral del Consejo Nacional de Investigaciones Científicas y Técnicas (CONICET) con sede en el Instituto de Investigaciones en Ciencias de la Educación de la UBA. 
em escolas secundárias urbanas periféricas de La Plata. Para a realização da pesquisa socioeducativa, optou-se por uma abordagem qualitativa com delineamento exploratório. A coleta de dados foi realizada por meio de entrevistas em profundidade com 40 alunos de duas instituições atendidas por uma população com características socioeconômicas e culturais de vulnerabilidade. A análise dos dados foi realizada de acordo com a teoria fundamentada de Glaser e Strauss. A partir dos depoimentos obtidos, pode-se afirmar que o rosto e a cor da pele são qualidades físicas que operam como signo de distinção e diferenciação entre sujeitos e grupos. Certos traços faciais, assim como certos tons de pele, são considerados inferiores, atribuindo a seus portadores todas as outras características negativas em um processo de generalização e essencialização que chamamos de racismo corporal. Aqueles que são objeto desses processos de rotulagem vivenciam emoções marcadas pela vergonha, raiva, nojo e pelo medo de se sentir excluído que produzem dores sociais difíceis de suprimir.

Palavras-chave: Racismo; Jovens; Corpos; Emoções.

\title{
THE RACISM OF THE BODY IN THE LIGHT OF THE CONTRIBUTIONS OF NORBERT ELIAS 'FIGURATIONAL SOCIOLOGY
}

\begin{abstract}
This article takes up the contributions of the figurative sociology of Norbert Elias to deepen the idea of racism of the body, elaborated with the purpose of approaching the approach to the stigmatization processes that significantly involve the corporality of young people. The objective of the study that frames this work is to understand the senses that students construct on bodies and emotions and establish their link with the production of violence in peripheral urban secondary schools of La Plata. To carry out the socio-educational research, a qualitative approach with an exploratory design was chosen. Data collection was carried out through in-depth interviews with 40 students from two institutions attended by a population with socio-economic and cultural characteristics of vulnerability. Data analysis was performed according to the grounded theory of Glaser and Strauss. From the testimonies obtained, it can be argued that the face and skin color are physical qualities that operate as a sign of distinction and differentiation between subjects and groups. Certain facial features as well as certain skin tones are considered inferior, assigning to their bearers all other negative characteristics in a process of generalization and essentialization that we call body racism. Those who are the object of these labeling processes, experience emotions marked by shame, anger, disgust and fear of feeling excluded that produce social pain that is difficult to suppress.
\end{abstract}

Keywords: Racism; Youths; Bodies; Emotions. 


\section{Introducción}

La convivencia se enmarca en un entramado de vínculos sociales cuya matriz emocional se codifica y decodifica a través del lenguaje de los cuerpos (KAPLAN, 2013). Los comportamientos, expresiones y signos corporales de las y los estudiantes de sectores subalternos entran en conflicto con el orden social establecido desbordando los modelos de juventud. Las expresiones estigmatizantes y racistas que tienen lugar en el cotidiano escolar, en las redes sociales y en otros espacios de socialización que vivencian las y los jóvenes, constituyen los ladrillos de un muro afectivo que marca proximidades físicas y distancias simbólicas entre individuos y grupos (KAPLAN, 2016, KAPLAN; SZAPU, 2020).

Los rostros, y más particularmente la piel, como elementos principales y visibles de la interacción cotidiana, operan como signos que pueden legitimar o deslegitimar a sujetos o grupos. La portación de ciertos rasgos faciales o determinados tonos de piel son asociados a características y actitudes consideradas como negativas. Uno de los hallazgos principales del trabajo ${ }^{1}$ que da marco al presente artículo, gira en torno al modo en que estas formas de racismo operan sobre la construcción subjetiva de los sujetos a partir de emotividades ligadas a la vergüenza, el asco, el miedo a la exclusión y la sensación de rechazo.

El propósito de este escrito es recuperar aquellas ideas desarrolladas en la sociología figuracional de Norbert Elias que puedan echar luz a la problemática planteada y permitan profundizar en los análisis de los testimonios recogidos durante la investigación. Pensar la relación entre individuo y sociedad, el concepto de configuración, la conformación de un ellos y un nosotros y las principales nociones respecto a cómo entender el vínculo entre cuerpos y emociones son algunas de las contribuciones que pueden resultar significativas al reflexionar en torno a los procesos de estigmatización que tienen lugar en las experiencias juveniles.

Para iniciar este recorrido es imprescindible partir desde el rechazo hacia los dualismos que Elias sostiene a lo largo de su obra. El autor plantea que en la tradicional escisión entre lo psicológico (individual) y lo social se esconde una concepción de estas nociones como compartimentos estancos e independientes el uno del otro:

Conceptos como «individuo»y «sociedad» no se remiten a dos objetos con existencia separada, sino a aspectos distintos, pero inseparables, de los mismos seres humanos y que ambos aspectos, los seres humanos en general, en situación de

\footnotetext{
${ }^{1}$ La tesis doctoral que da lugar al presente artículo lleva como título: "Violencias, cuerpos y emociones en los procesos de estigmatización. Un estudio socioeducativo desde la perspectiva de jóvenes de escuelas secundarias". La misma se enmarca en los proyectos UBACYT 2018: "Violencias, estigmatización y condición estudiantil. Una sociología de la educación sobre las emociones y los cuerpos" y PIP CONICET "La construcción social de las emociones y la producción de las violencias en la vida escolar. Un estudio sobre las experiencias de estudiantes de educación secundaria de zonas urbanas periféricas", ambos con sede en el Programa de Investigación "Transformaciones sociales, subjetividad y procesos educativos", bajo la dirección de la Dra. Carina V. Kaplan, del Instituto de Investigaciones en Ciencias de la Educación, Facultad de Filosofía y Letras, Universidad de Buenos Aires.
} 
normalidad, sólo pueden comprenderse inmersos en un cambio estructural. Ambos conceptos tienen el carácter de procesos y no es posible en absoluto hacer abstracción de este carácter de proceso en una construcción teórica que se remita a los seres humanos. Por el contrario, resulta imprescindible incluir este carácter procesal en la teoría sociológica y en las otras que se refieran a los seres humanos (ELIAS, 1987, p. 16).

El carácter de proceso propuesto por al autor permite realizar una lectura respecto de las relaciones sociales a través de la imbricación entre lo subjetivo y lo objetivo, entre lo individual y lo social, desde un enfoque que toma en consideración las variables temporales y contextuales, siempre en su carácter dinámico.

Los individuos conforman una sociedad, la cual no puede tener entidad sin aquellos. A su vez, la configuración individual del ser humano depende de la estructuración de las relaciones humanas. Las estructuras individuales y las estructuras sociales deben investigarse como algo mutable y en flujo continuo, es decir que se van modificando a lo largo del devenir histórico (DI NAPOLI; SZAPU, 2016, p. 186).

Una teoría de la sociedad no puede ser abordada sin tener en cuenta el proceso de individuación; esta conjunción interdependiente es la que sostiene el autor al describir el proceso de la civilización a través de sus investigaciones sociogenéticas y psicogenéticas (ELIAS, 1987).

Es a partir de este entrelazamiento entre individuo y sociedad que resulta posible afirmar que la reunión de muchas personas, dadas sus vinculaciones y dependencia recíproca, forman algo distinto a la mera suma de muchas individualidades y "constituyen entre sí entramados de interdependencia o figuraciones con equilibrios de poder más o menos inestables del tipo más variado como, por ejemplo, familias, escuelas, ciudades, capas sociales o estados" (ELIAS, 2008, p. 16). Surge así el concepto de figuración o configuración, que será de suma utilidad para comprender las relaciones entre sujetos y grupos.

En su estudio de caso publicado como Establecidos y marginados. Una investigación sociológica sobre problemas comunitarios (2016), Elias y Scotson describen las relaciones de poder entre dos grupos estructuralmente similares (que comparten clase, nacionalidad y etnia) de una pequeña comunidad llamada Winston Parva. La socio-dinámica de la estigmatización permite advertir cómo una de las figuraciones, a la que denominan como establecidos, tiende a erigirse a sí misma como un grupo humano de orden superior con respecto a los otros (forasteros, excluidos o marginados según las diferentes traducciones).

Dicha investigación suministra elementos de juicio suficientes para situar las violencias en un microcosmos social donde se observa que la capacidad de un grupo de apuntalar la inferioridad humana del otro y de hacerla valer, es una función de una figuración específica que ambos grupos forman entre sí. La estigmatización hacia ciertos grupos sociales (por su origen étnico, de clase, de género, o sus rasgos físicos) no se puede confundir con "prejuicios" más o menos 
personales ni deben ser estudiados únicamente en la psicología individual de los estigmatizadores. "Un grupo puede estigmatizar efectivamente a otro sólo mientras esté bien establecido en las posiciones de poder de las que se excluye al grupo estigmatizado" (ELIAS; SCOTSON, 2016, p. 33).

La estigmatización absoluta de los establecidos (incluidos, con creencias de superioridad) hacia los marginados (excluidos, con creencias de inferioridad) denota un profundo desequilibrio de poder: el darles un valor de inferioridad es un instrumento para mantener su supuesta superioridad social. Esto viene asociado en muchas ocasiones a lo que los autores llaman fantasía colectiva desarrollada por los establecidos, que busca justificar la aversión hacia el grupo excluido y puede tener su anclaje en aspectos físicos.

Esto ilustra de manera muy gráfica el funcionamiento y también la función de las fantasías del grupo dominante en relación con sus grupos marginados: el estigma social que sus miembros adjudican al grupo marginado se transforma en su imaginación en un estigma material, se cosifica. Se muestra como algo objetivo, algo que la naturaleza o los dioses implantaron sobre los marginados. Así, el grupo que estigmatiza queda eximido de cualquier culpa: no somos nosotros, implica una fantasía de este tipo, los que han puesto el estigma sobre estas personas, sino los poderes que hicieron el mundo (ELIAS; SCOTSON, 2016, p. 50).

En su trabajo explican este proceso a partir de la mención del caso de Japón, en donde los burakumin soportan la carga de ser considerados como sucios y a duras penas humanos. A este grupo se le atribuye una mancha azul de nacimiento debajo del brazo como signo hereditario que reafirma su posición de paria. Una marca corporal atribuida a los forasteros y entendida como un símbolo (en general denigratorio) de lo que este grupo representa para los establecidos. De esta manera se refuerza la diferenciación entre unos y otros.

La referencia a un color de piel diferente y a otras características biológicas o innatas de los grupos que reciben -o recibieron- un trato de inferioridad por parte de un grupo establecido tiene la misma función de objetivar en esta relación que la referencia al estigma azul imaginario de los burakumin. El signo físico sirve de símbolo tangible de la anomia asumida del otro grupo, de su valor reducido en términos humanos, de su maldad intrínseca; como la fantasía del estigma azul, la referencia a estos signos «objetivos» tiene una función en la defensa de la distribución de las oportunidades de poder existentes, así como una función justificatoria (ELIAS; SCOTSON, 2016, p. 50-51).

Se trata de una marca que establece una diferencia, y se convierte así en un estigma que alude a la inferioridad de un grupo objetivamente excluido. De este modo, el par superioridad/inferioridad parece ser más tangible e incluso legitimarse en el discurso de los establecidos reafirmando su poder, al atribuir esta inferiorización a ciertos rasgos "naturales". 
El cuerpo socializado funciona bajo una matriz de segregación que repercute en los procesos de exclusión negando la subjetividad de quien no responde a los cánones socialmente establecidos: "los grupos más poderosos se consideran a sí mismos «mejores», como si estuvieran dotados de un tipo de carisma grupal, de una virtud física que comparten todos sus miembros y de la que carecen los demás" (ELIAS; SCOTSON, 2016, p. 28).

Estas reflexiones sobre los procesos de estigmatización son atravesadas por un factor histórico al pensar las dinámicas entre distintas grupalidades a lo largo del tiempo. Según los autores, en un primer momento, diferentes grupos humanos fueron desarrollándose en varias partes del mundo y adaptándose al ambiente físico que los rodeaba a través de amplios períodos de aislamiento respecto a otros grupos. Siguiendo el ejemplo de la India y su división en castas, muestran que, en un segundo momento, con la expansión territorial, los grupos fueron entrando en contacto unos con otros en calidad de conquistadores $y$ conquistados $\mathrm{y}$, por ende, como establecidos y forasteros.

El punto de partida fue la sujeción gradual de los primeros habitantes de la India a manos de los invasores del norte que los conquistaron. Aparentemente, estos llegaron de las estepas del sur de Rusia a través de Irán, hablaban una lengua indo-europea y, en algunos documentos, se referían a sí mismos como arios de tez clara, fácilmente distinguibles por su apariencia física de las tribus de piel oscura a las que volvieron sujetas de su mandato (ELIAS; SCOTSON, 2016, p. 66).

Los rasgos físicos que diferenciaban a un grupo de otro comienzan a instalarse como diferenciales de poder entre conquistados y conquistadores, entre un ellos y un nosotros, fabricando identidades y demarcando pertenencias.

Fue como resultado de este largo proceso de entremezcla, en el que grupos con diferentes características físicas se volvieron interdependientes como amos y esclavos, o en otras posiciones con grandes diferenciales de poder, que las diferencias en la apariencia física se convirtieron en señales de la pertenencia a grupos con distintos índices de poder, estatus y normas diferentes (ELIAS; SCOTSON, 2016, p. 66).

De allí que, comprender los usos del cuerpo y su tratamiento social son fundamentales a la hora de pensar las taxonomías sociales, las formas de percepción y clasificación que operan hoy en día; especialmente, en contextos de marginalidad donde entran en juego estéticas particulares que funcionan como mecanismos asociados a discursos racistas y criminalizantes:

La apariencia de pobre (el hábito corpóreo como indicio de clase o, lo que es equivalente, el cuerpo tratado socialmente), por ejemplo, está asociada a la del ser violento y a la incivilidad en general, lo que genera una suerte de discurso racista sobre los jóvenes surcados por la condición de marginalidad y subalternidad (KAPLAN, 2012, p. 29). 
Es a partir de allí que desarrollamos el concepto de racismo del cuerpo con la intención de alcanzar una mayor comprensión respecto a los procesos de estigmatización que involucran de manera significativa aspectos de la imagen corporal de las y los jóvenes. "El racismo del cuerpo se expresa en los modos de la interacción escolar donde unos grupos se creen superiores y subsumen a los otros a quienes consideran de menor valía social" (KAPLAN; SZAPU, 2019, p. 110) mediante el ejercicio de la violencia ya sea física o verbal. Las categorías de etiquetamiento utilizadas por las y los jóvenes...

No pueden ser consideradas como intrínsecas de ciertos sujetos o grupos (ni siquiera la atribución de rasgos físicos) sino que son cualidades percibidas socialmente donde se establece el juego entre grupos superiores e inferiores, entre el sentimiento de mayor y menor valía social, entre auto-imágenes diferenciadas (KAPLAN, 2009, p. 7).

Las formas de discriminación que se profesan debido a la apariencia física, ya sea por el color de piel, la condición étnica, la identidad de género o el rostro, se anclan en determinados contextos culturales que le dan sentido. Estos condicionamientos materiales y simbólicos están atravesados por una expresión del racismo de clase donde la piel opera como un eufemismo que cristaliza el origen de cuna prefijando destinos (KAPLAN, 2016). Los juicios estigmatizantes generan sentimientos de exclusión que producen un dolor social que impacta en la constitución subjetiva de las y los estudiantes.

Al describir a los jóvenes pertenecientes a los sectores excluidos de Winston Parva, Elias y Scotston (2016) planteaban que:

Era profundamente difícil para los jóvenes que crecían en familias de este tipo escapar de su posición de marginados. Es indudable que esta posición tenía una profunda influencia en el desarrollo de la imagen que de sí mismos tenían, en su sentimiento de identidad y de orgullo en relación con los otros, en el desarrollo de su personalidad (p. 198-199).

Al estudiar los sentidos en torno a la corporalidad y su potencial como signo de distinción y espacio de tensión en la conformación de grupos, es que el concepto de racismo del cuerpo toma relevancia y puede resultar de utilidad para analizar las dinámicas de estigmatización y sus consecuencias en la constitución de identidades juveniles signadas por el dolor social.

\section{Metodologia}

La perspectiva constructivista adoptada permite afirmarse en el supuesto de que es necesario superar, en la práctica de investigación socioeducativa, la escisión entre las concepciones objetivistas y subjetivistas (BARANGER, 2004; BOURDIEU, 1988; ELIAS, 1987, 1990, 2008; GUTIÉRREZ, 2005; KAPLAN, 2008). En el análisis de las experiencias corporales y emotivas en los procesos 
de estigmatización es preciso dar cuenta de la dialéctica entre los sentidos que construyen los actores en su interacción y los condicionamientos objetivos.

Lejos de una mirada sustancialista, se propuso una matriz relacional que permitió dar cuenta de la constitución de los individuos y grupos en configuraciones sociales específicas (BOURDIEU, 1988; ELIAS, 1990, 2016; KAPLAN, 2016). La intención giró en torno a comprender las acciones de los individuos y grupos insertas en una trama que involucre su historia y su entorno (SIRVENT, 2006). Desde la investigación cualitativa, (VASILACHIS DE GIALDINO, 2006), se sostuvo el interés por comprender la manera en que la complejidad de las interacciones sociales se expresa en la vida cotidiana, a la vez que interpretar los significados que los actores le atribuyen. De este modo toma sentido referirse a los procesos de socialización y subjetivación en la singularidad de las instituciones escolares.

Se partió del supuesto de que existe una dimensión simbólica-subjetiva de la desigualdad y las violencias en la escuela que es preciso estudiar y caracterizar. Desde un abordaje cualitativo (PORTA; SILVA, 2003) y siguiendo un diseño interpretativo (GÓMEZ-GÓMEZ, 1995, GUTIÉRREZ, 1999) se asumió que es preciso oponerse al teoricismo entendido como una elaboración conceptual por fuera de la indagación empírica, así como también al empirismo que reduce la investigación a una toma de datos con autonomía de la teorización (BOURDIEU, CHAMBOREDON y PASSERON, 2002).

El relevamiento de datos cualitativos se llevó a cabo mediante la realización de cuarenta entrevistas en profundidad a partir de una guía semiestructurada (YUNI y URBANO, 2014) a jóvenes de escuelas secundarias públicas de gestión estatal de la Ciudad de La Plata, Provincia de Buenos Aires, Argentina. Para ello, se estableció un muestreo intencional (MARRADI, ARCHENTI y PIOVANI, 2018), no representativo, de estudiantes de dos instituciones enclavadas en zonas urbanas periféricas a las que concurren poblaciones con características socioeconómicas y culturales de vulnerabilidad. La selección de los sujetos a entrevistar se realizó siguiendo los criterios de accesibilidad, heterogeneidad y saturación teórica (GLASER y STRAUSS, 2009).

Los análisis se realizaron en el marco de la teoría fundamentada. Marradi, Archenti y Piovani (2018) sitúan, dentro de los estudios cualitativos, a la corriente denominada de teoría fundamentada que aspira a generar teoría a partir de datos empíricos, buscando un diálogo entre teoría y empiria. Este tipo de análisis resultó pertinente para el objeto-problema propuesto en tanto dio lugar a la construcción metodológica a partir de la inducción, la selección basada en criterio de las unidades de análisis y la búsqueda de la saturación teórica como guía orientador apara el trabajo de campo (MARRADI, ARCHENTI y PIOVANI, 2018). La información cualitativa fue procesada mediante la utilización de un software para datos no estructurados (Atlas $\mathrm{Ti}$ ), siguiendo las estrategias de la teoría de Glaser y Strauss (2009), en lo que se refiere a procedimientos de categorización.

Dado que se parte de un marco teórico, el trabajo con las dimensiones empíricas del estudio estuvo orientado, ante todo, a profundizar el análisis en función de las hipótesis/conjeturas. Se fue avanzando con apoyatura empírica en dirección de las hipótesis/conjeturas sin pretender validarlas, sino con la 
intención de hacer emerger nuevas categorías a partir del trabajo interpretativo para enriquecer los aportes teóricos del enfoque adoptado y formular nuevas hipótesis/conjeturas, dando así continuidad al proceso de investigación.

\section{Resultados e discussões}

A través de la voz de las y los estudiantes se recuperaron significados y vivencias que permiten comprender el papel del cuerpo y las emociones en los procesos de estigmatización. El análisis de los testimonios de jóvenes atravesados por condiciones materiales y simbólicas de marginalidad, permite interpretar ciertos rasgos corporales que operan como signos de distinción e identificación entre grupos.

Al indagar respecto a las situaciones que son motivo de conflicto, los entrevistados refieren a ciertos aspectos de la corporalidad. Frente a la pregunta sobre los detonantes de agresiones, ya sean físicas o verbales, estas son algunas de las respuestas obtenidas:

Le pegamos porque tiene cara de pobre. Es negra y paraguaya...

\section{(Estudiante varón de 6to año)}

(Estudiante mujer de 3er año)

Te humillan todo el tiempo, porque no tenés zapatillas de marca

..a mí me cargan por ser petisa.

(Estudiante varón de 3er año)

(Estudiante mujer de 3er año)

Cualidades físicas como el color de piel, el uso de determinada ropa, el porte o el hecho de tener "cara de pobre" aparecen de manera recurrente entre las respuestas obtenidas frente al interrogante respecto a las violencias en las escuelas. A partir de este proceso de etiquetamiento que denominamos racismo del cuerpo, se instaura una relación de inferioridad-superioridad que se ancla en aspectos de la corporalidad y tiene consecuencias en las emotividades de las y los jóvenes. En estos argumentos se establece una distancia entre quienes son objeto de agresiones por poseer ciertos atributos físicos y quienes se adjudican la potestad de agraviar a los otros. Estas relaciones de poder dan lugar a la conformación de dos grupos que fácilmente pueden ser identificados como nosotros y ellos (ELIAS; SCOTSON, 2016; KAPLAN; KROTSCH, 2018; KESSLER, 2012).

\section{Entrevistador: ¿Qué se dicen?}

Entrevistada: Negro cabeza. Se te quemó la cuna cuando naciste. De todo les dicen. Vos sos blanca, no hablés nada. O a los negros, los negros se tienen que morir si no valen nada.

Entrevistador: ¿Y los que molestan cómo se consideran, grises?

Entrevistada: Es así. Encima hay un morocho que critica a los negros. Eso es lo que no entiendo.

(Estudiante mujer de 2do año) 
En el testimonio anterior se expresa una diferenciación entre "negros" y "blancos" en la que se denota el tono de las agresiones entre los distintos grupos, así como se muestra hacia donde se inclina la balanza de poder en cuanto a quien está en posición de estigmatizar o ser estigmatizado.

Más allá de utilizar distintos modos de adjetivación para referirse a estos conjuntos, las y los entrevistados suelen referir a una clasificación de la juventud en dos grandes grupos antagónicos.

\section{Entrevistador: ¿Hay distintos grupos de jóvenes en tu escuela?}

Entrevistada: Si, los que se hacen los caretas ${ }^{1}$. Hay algunos, pero en este grupo uno que otro se hace el careta y listo.

Entrevistador: ¿Y hay algún otro grupo?

Entrevistada: Si, están los turros ${ }^{2}$, que se visten... es otro nivel ya. No es careta, ya directamente pasó a ser un villero ${ }^{3}$.

Entrevistador: ¿Es lo mismo turro y villero?

Entrevistada: Si.

\section{(Estudiante mujer de 2do año)}

Los relatos dan cuenta de la discriminación por parte de los incluidos frente a los excluidos mediante lo que Van Dijk (2007) denomina discurso racista. Para el grupo establecido se utilizan adjetivaciones tales como "chetos"4 o "caretas", mientras que para el marginado predominan tipificaciones como las de "negros", "turros" o "villeros". La caracterización de unos y otros gira en torno a aspectos del cuerpo socialmente tratado y a otras cualidades que van más allá de lo físico. Entre estas características, el rostro o la cara, como elemento central del cuerpo, juega un rol fundamental en el desarrollo de los vínculos entre jóvenes y en la construcción de subjetividades en torno a estas interacciones.

Ninguna parte del cuerpo es tan importante para la identidad del yo como la cara. Y el rostro es también lo que muestra con mayor claridad en qué medida está ligada la identidad del yo con la continuidad del desarrollo desde la infancia hasta la vejez (ELIAS, 1990, p. 217).

En el lenguaje cotidiano, la cara vale por la persona completa, por el sentimiento de identidad que la caracteriza y por la estima que recibe de los otros. Puede interpretarse como "una medida de la dignidad social de la que un actor es objeto" (LE BRETON, 2010, p. 124). El cuerpo, y más particularmente el rostro, dado su carácter social expresado a través de sus marcas, más o menos visibles, más o menos invisibles, es productor de subjetividades (KAPLAN, 2016).

En las dinámicas de estigmatización, la asignación de etiquetas o motes puede recaer sobre un sujeto en particular o sobre un conjunto humano que

\footnotetext{
${ }^{1}$ Se utiliza para denominar a una persona hipócrita, falsa.

2 Mala persona.

${ }^{3}$ Se dice de quien vive en una villa misera

${ }^{4}$ Se dice de quien pertenece o simula pertenecer a un sector social alto mediante la ostentación.
} 
porta determinados rasgos faciales. Así relata una estudiante las razones por las que ella y su grupo de amigas sienten miedo en la calle:

\section{Entrevistador: ¿̇e pasó de sentir miedo en la calle alguna vez?}

Entrevistada: Sí, porque por ahí voy con mis amigas y dicen "hay negros, crucemos".

Entrevistador: ¿̇Y qué les da miedo?

Entrevistada: Y, cuando están los chicos que son... te das cuenta que son villeritos, por la cara.

(Estudiante mujer de 5to año)

A través de la observación del rostro del otro se determina su pertenencia al grupo de los "negros" o "villeritos" y se enciende un llamado de alerta, de temor por considerar que el extraño no se ajusta a las normas sociales establecidas.

En su raíz se encuentra el miedo producido por el contacto con un grupo que ante nuestros ojos, así como ante los de nuestros compañeros, es anómico. Sus miembros rompen las reglas que uno está obligado a observar, de cuya obediencia dependen tanto nuestro respeto propio como el respeto por nuestros compañeros (ELIAS; SCOTSON, 2016, p. 69-70).

Los sentimientos de miedo y el rechazo por parte de los integrantes del grupo establecido, esconden una atribución de distintas cualidades consideradas como negativas o anómicas hacia los sujetos sospechosos de pertenecer al grupo marginado.

\section{Entrevistador: ¿̇Y tuviste miedo en la calle alguna vez? \\ Entrevistada: Sí... Acá es un desastre. Cuando se juntan así, grupos con motos que están en las esquinas o algo, te das cuenta. Por el aspecto. \\ Entrevistador: ¿Qué tienen, cómo son? \\ Entrevistada: Primero que están dados vuelta mal, porque fuman, toman y no importa la hora. Y están con los camperones largos, pantalones deportivos. Aparte por la cara también te das cuenta.}

(Estudiante mujer de 5to año)

El hecho de taparse la cara, ya sea mediante el uso de gorras o capuchas, es otro de los elementos identificado como distintivo entre ambos grupos y es motivo de temor de unos para con los otros.

Entrevistador: ¿Qué es lo que te hace ir con precaución? Entrevistado: Que ellos andan con capucha, así y no se les ve la cara, andan como en grupo, fumando con una bolsa. Ya más o menos te podés dar cuenta.

Entrevistador: ¿̇Y por qué te parece que la gente le tiene miedo al que está con gorra, al que está con capucha?

Entrevistado: Y por lo general porque se nota que ocultan algo... si anda con capucha y anda todo así (imita con el cuerpo la posición 
de estar encorvado) pueden estar ocultando algo. Si vos ves a alguien así no es de maldad pensar que podría tener un arma. Por lo general la gente que roba va con capucha para que no les vean la cara o no los identifiquen y también porque tienen el buzo ahí para guardar el arma en los bolsillos.

(Estudiante varón de 5to año)

En referencia a los rostros como parte fundante de la imagen corporal, Kaplan (2013) nos recuerda que éstos connotan signos de distinción en una dinámica relacional atravesada por el poder:

Los sentimientos sobre el rostro terminan por vincularse a las creencias y sentimientos de superioridad e inferioridad de individuos y grupos que se cristalizan en prejuicios y creencias que enaltecen o denigran a quienes no cumplen con determinadas características que son valoradas positivamente en una determinada cultura (KAPLAN, 2013, p. 50).

La portación de rostro, junto a otros rasgos corporales, son asociados a determinadas pautas de comportamiento de connotación negativa como la delincuencia y, por ende, generan miedo y precaución. De este modo se justifica el uso de diferentes prácticas relacionadas al racismo del cuerpo. Recordemos que las lógicas del racismo están sustentadas por un principio de inferiorización por parte de quienes detentan una posición y una creencia de superioridad.

La exclusión y la estigmatización de los marginados a manos del grupo establecido fueron, por lo tanto, armas poderosas que este último utilizó para conservar su identidad, afirmar su superioridad y mantener a los otros firmemente en su lugar (ELIAS; SCOTSON, 2016, p. 31)

Otra de las fuentes principales de esta discriminación entre grupalidades es el color de piel. Quienes poseen tonalidades percibidas como más claras se posicionan a sí mismos en un lugar de superioridad frente a los demás. La piel del rostro encarna la zona sensible del vínculo con los otros.

Los morochos así, bien morochos, son del grupo de los villeros. $Y$ los de piel, tez blanca, son los caretas (ríe levemente). O piel, sí, no sé, blanca. Yo lo digo porque es lo que veo. Porque veo grupitos así de gente careta que tienen la piel blanca. Y después el grupo de los villeros que son morochos.

(Estudiante varón de 5to año)

Generalmente, los turros son más morenitos, son más morochitos. No son negros negros pero son más morenitos. No como yo que soy blanco blanco. Y los chetos son blancos, como yo. Absolutamente blancos. Así que esa es la principal diferencia, los más morochitos de todos serían los turros.

(Estudiante varón de 2do año) 
Los grupos y quienes los integran, son definidos mediante parámetros corporales entre los que el tono de piel juega un rol principal. La tez oscura es asociada a toda una serie de características que van desde aspectos físicos (cierto estilo para vestirse, el uso de tatuajes o piercings y un corte de pelo en particular) hasta cualidades de la persona (querer pelearse todo el tiempo, el consumo de droga y alcohol, formar parte de acciones delictivas, tener un modo de hablar más vulgar).

Un careta se vestiría con un jean, o un pantalón bermuda, pero de jean. Una remerita caretita, linda. El negro ropa deportiva pero toda rota. Algo así vendría a ser. Porque sé que hay mucha gente que se viste con ropa deportiva, pero porque le gusta. Y aparte bien cuidada bien, nueva. Hay como una diferencia.

(Estudiante mujer de 5to año)

Entrevistado: Y, generalmente los chetos son los que tienen, ¿cómo te puedo decir?, que se preocupan más por los temas del colegio, salen temprano y... Por ejemplo, mi grupo del curso, salimos temprano, aprovechamos el día y vamos un rato a la plaza a tomar mate. Y capaz que algunos grupos no, dicen "bueno, me voy a mi casa. A ver si me mira alguien de mi familia y me dice ¿qué hacés acá?". Son más responsabilidad que otra cosa.

\section{Entrevistador: ¿Y los turros?}

Entrevistado: $Y$, esos andan perdidos en la vagancia (risas). Ya ni les importan las materias, no les importa nada. Entran si tienen ganas y sino los ves afuera, sentados. Ya están perdidos en la vagancia.

(Estudiante varón de 5to año)

Claro, ella actúa como negra en el sentido de... (hace una pausa) Quiere pelear todo el tiempo, habla como negra. Como una persona que vivió en la calle (risas).

(Estudiante mujer de 5to año)

En los fragmentos de entrevista previamente citados se hace referencia a diversas características que permiten armar una especie de tipificación para cada uno de los grupos. Desde la preocupación por el estudio, la presencia familiar y la actitud frente a los demás hasta la vestimenta, el modo de hablar y los espacios que habitan. A estos se le suman, en otros testimonios no referenciados, el uso de tatuajes y piercings, el tipo de música que escuchan, los boliches que frecuentan y toda otra serie de rasgos que son utilizados para diferenciar entre "negros" y "caretas". Se produce en esta caracterización una violencia que recae sobre quienes son estigmatizados.

Esta identidad se forma con tal cohesión que cualquier individuo que sea asociado al grupo marginado por poseer algunas de las cualidades del conjunto, cumplirá per se con todas las otras características asignadas al mismo como se refleja en el siguiente testimonio al expresar que "lo ponés en la bolsita del villero, del negro": 
Entrevistada: Pasa un negro y... Pasa un pibe, golpea la puerta fuerte o grita y le decimos "negro de mierda".

Entrevistador: ¿Pero por qué? ¿Qué es ser "negro", "negro de mierda"? ¿Es golpear la puerta fuerte ser "negro de mierda"?

Entrevistada: Si, desubicado, eso también. Porque no tiene respeto por nada y cuando pasa vos decís "negro de mierda" y lo ponés en la bolsita del villero, del negro.

(Estudiante mujer de 5to año)

Tal es así, que como en el caso de los burakumin descripto por Elias y Scotson (2016) se genera sobre los marginados una suerte de mística o fantasía colectiva mediante la que le atribuyen a este grupo una cualidad intrínseca como la de poseer un "alma de negro".

\section{Entrevistador: ¿Cómo son esos grupitos ${ }^{1}$ ?}

Entrevistada: Por ejemplo, estos que te digo que se juntan en la esquina, que fuman porro ${ }^{2}$. O a veces son más grandes y ahí si me da más cosa.

Entrevistador: ¿̇ qué son, son tipo caretas a son tipo negros $^{3}$ ?

Entrevistada: No, tipo negrada (ríe). Si fueran caretas no me darían miedo.

\section{Entrevistador: ¿Por qué?}

Entrevistada: Porque no, porque los ves más tranquilos. Un pibe que es más negro decís anda robando.

Entrevistador: ¿Más negro de piel?

Entrevistada: No, no. Negro de alma (ríe).

(Estudiante mujer de 5to año)

Llegado a este punto, surgen interrogantes respecto a la construcción subjetiva de las y los jóvenes: ¿Qué emociones vivencian quienes son objeto de burlas y discriminaciones? ¿Cómo afectan estas emotividades a su constitución subjetiva? ¿Cómo influyen el tono de piel, la portación de rostro y la condición de pobreza en este proceso de estigmatización?

En primer lugar, vale reparar en los efectos sobre la emotividad de quienes son estigmatizados. En el siguiente testimonio, la joven argumenta sentirse mal al haber recibido la adjetivación de "negra" por parte de una amiga. Pero resulta interesante detenerse también en la última frase, donde manifiesta haber sentido asco, emoción que Elias relaciona con otras como la vergüenza, el miedo, la ira, entre otras.

Entrevistador: ¿Alguna vez te pasó que te hagan sentir mal? Entrevistada: Sí, puede ser por cómo esté vestida. Pero nunca fui tan crota como para que me digan... Por ahí negra, negra sí puede ser.

\footnotetext{
${ }^{1}$ Haciendo referencia a los grupos que le generan miedo cuando se los cruza en la vía pública.

${ }^{2}$ Cigarrillo de marihuana.

${ }^{3}$ Retomando categorías ya utilizadas por la entrevistada
} 


\section{Entrevistador: ¿Te dijeron negra y te hizo sentir mal?}

Entrevistada: Sí. Una amiga, conocida. Estaba con su bebé y le dice "Ah, mirá la negra", qué se yo. Me dio un asco, pero no le dije nada. No, no le dije nada.

(Estudiante mujer de 5to año)

Las emociones de asco, vergüenza, ira o miedo a sentirse excluido producen un dolor social que es padecido por quienes son depositarias de juicios de valor estigmatizantes. Lo complejo es que estos estados emocionales llegan a ser percibidos como algo "natural".

La mayoría de los adultos olvida o reprime tempranamente el hecho de que sus sentimientos de vergüenza y de desagrado, de placer y de disgusto fueron modelados y regulados a través de la presión y la coacción externas. Todo esto se les antoja como algo muy personal, como algo «interno», como algo que les ha sido dado por naturaleza (ELIAS, 1987, p. 170).

La siguiente joven relata el modo en que siente dolor cada vez que le dicen negra, más allá de utilizar ella también dicho adjetivo en forma despectiva.

Entrevistada: Por lo único que me podría haber sentido mal... Por ejemplo, mi madrastra, que es la persona que está con mi papá, decía: "Esa es una negra de mierda". A veces te toca un poco, porque si dice eso... tampoco yo soy tan blanca, entonces te queda ahí. O por ahí mi primo me dice "negra", eso sí me da bronca. Yo también lo digo, pero bueno, cuando me lo dicen igual me duele.

(Estudiante mujer de 5 to año)

Quienes son objeto de este etiquetamiento atraviesan experiencias en las que determinados sentimientos van constituyendo emotividades signadas por un dolor social. Tales son los alcances de este padecimiento y su naturalización que los marginados terminan asumiendo su posición y auto percibiéndose como sujetos de inferior valor social en relación a los integrantes del grupo establecido.

En la misma manera en que los grupos establecidos normalmente consideran la superioridad de su poder como un signo de su valor humano más elevado, los grupos marginados, mientras el diferencial de poder sea grande y la sumisión inevitable, experimentan emocionalmente su inferioridad de poder como un signo de inferioridad humana (ELIAS; SCOTSON, 2016, p. 40-41).

Así lo expresa uno de los jóvenes entrevistados:

Entrevistador: Vos decís que a tu compañero no le gusta que le digan negro. Pero a vos también te dicen negro, ¿te gusta que te digan negro?

Entrevistado: Tampoco, no me gusta. Pero es lo que me tocó y tengo que afrontar la realidad.

Entrevistador: ¿Cuál es la realidad? 
Entrevistado: iQue me digan negro! Es mi color de piel y listo. No me importa.

(Estudiante varón de 2do año)

En las dinámicas de estigmatización previamente descriptas, ciertos sujetos se enfrentan ante la imposibilidad de alcanzar una representación simbólica del propio futuro que sea superadora de un presente doliente. La piel socializada funciona bajo una matriz de segregación que incide en los procesos de exclusión, negando la subjetividad del que es diferente, de quien no porta un tono de piel legitimado socialmente, produciendo un efecto de sufrimiento social. Este dolor social se va construyendo a partir de distintas experiencias que involucran sentimientos como el de vergüenza, asco y miedo a sentirse excluido.

\section{Palabras finales}

La importancia de enfocar la mirada en los procesos de estigmatización, y más particularmente en aquellas situaciones que involucran aspectos de la corporalidad, estriba en el peso que ejercen estas violencias sobre la construcción subjetiva de las y los jóvenes. Estudiar los cuerpos, y más particularmente los rasgos físicos que operan como signos de distinción entre pares, es también estudiar las emociones que surgen a partir de estas dinámicas. Realizar este análisis a la luz de los aportes de la sociología figuracional resulta fundamental dado que "la obra de Elias le da a la sociología de principios del siglo XXI un cúmulo de desafíos epistemológicos, teóricos y metodológicos a partir del continuo sociedad-cuerpo-emociones enlazados en una lógica de proceso" (VERGARA MATTAR, 2010, p. 33).

A lo largo de este artículo se ha intentado expresar en qué modos el rostro y el color de piel son dos elementos principales en la asignación de etiquetas de un grupo sobre otro. A estos rasgos le acompañan distintas cualidades corporales como pueden ser el porte, la vestimenta, el uso de tatuajes o piercing, y otros aspectos de la persona como los gustos por la música, los vínculos familiares, el modo de hablar, la relación con las drogas, el alcohol o la delincuencia, entre otras. Estas características se agrupan de tal modo de crear en el imaginario social dos tipificaciones que, según los testimonios recogidos, pueden identificarse como "negros" y "caretas".

Estos grupos conforman una figuración particular, donde uno de ellos detenta una posición de poder respecto al otro. Ellos y nosotros, o establecidos y marginados, se diferencian a partir del color de piel y la portación de rostro a través de actos de discriminación que denominamos como racismo del cuerpo. Los tonos más oscuros de piel se asocian a otras cualidades de la persona percibidas como negativas en un proceso de esencialización del que es diferente. La "cara de pobre", así como toda una estética asignada los marginados ("sucios", "delincuentes", "drogadictos", "villeros") le proporciona al grupo establecido un sustento de su posición de superioridad, a la vez que colabora en el mantenimiento de una cohesión al interior del mismo. 
Los síntomas de la inferioridad humana que un grupo establecido con poder elevado tiene mayores posibilidades de percibir en un grupo marginado con un poder reducido, y que sirven a sus miembros para justificar que su posición sea más elevada y como prueba de que su valor es más grande, suelen generarse en los miembros del grupo inferior -inferior en términos de su índice de poder- por las mismas condiciones de su posición de marginados y por la humillación y opresión concomitantes. En ciertos aspectos, son las mismas en todo el mundo. La pobreza -un bajo nivel de vida- es una de ellas (ELIAS y SCOTSON, 2016, p. 40).

Estas prácticas traen aparejadas, para quienes son objeto de distintos tipos de violencias (ya sean estas simbólicas o no), emotividades signadas por sentimientos de vergüenza, asco, miedo a la exclusión, entre otros.

La coacción y la continencia a las que hay que someterse, así como el miedo, la vergüenza y el disgusto que producen las infracciones, aparecen muy claramente [...] como una coacción social, como vergüenza y miedo producidos por la presencia de otras personas (ELIAS, 1987, p. 176).

Dichas emociones se van interiorizando al punto de ser vividas como algo natural para los marginados, "es lo que me tocó" expresa uno de los entrevistados. El sentir asco o vergüenza a causa de una característica sobre la cual no se tiene margen de acción, produce un dolor social que parece difícil de suprimir. La autopercepción y la autoestima de quienes son estigmatizados se ve afectada por estas prácticas como lo manifiestan Elias y Scotson al referir a los jóvenes de Winston Parva que:

Debían buscar a tientas su identidad individual, su valor personal y orgullo desde el inicio como miembros de familias a las que no solo las personas de la «aldea», sino también algunas personas de su comunidad, trataban como marginados y, en ocasiones, casi como parias (ELIAS y SCOTSON, 2016, p. 198).

Gran parte de las y los estudiantes entrevistados en esta investigación manifestaron un sufrimiento social sobre el que no sabían cómo actuar para tramitarlo o mitigarlo. Parte de las estrategias que se infieren de los testimonios (las cuales no fueron objeto de este artículo), pueden interpretarse a la luz del concepto de cadenas de violencia desarrollado por Auyero y Berti (2013). Siguiendo esta línea de pensamiento, el sujeto que es víctima de situaciones de violencia en determinados espacios puede ser productor de violencias en otros. Estos actos de violencia, expresión del dolor social, pueden dirigirse hacia otro o hacia el propio cuerpo.

Es por ello que resulta importante, para todo aquel que desempeñe un rol como educador, hacerse las siguientes preguntas: ¿Cómo podemos colaborar en el reconocimiento de las emociones de las y los jóvenes? ¿Cómo ayudarlos a tramitar el dolor social? ¿Cómo intervenir pedagógicamente frente a situaciones de racismo? 


\section{REFERENCIAS}

AUYERO, Javier; BERTI, María Fernanda. La violencia en los márgenes. Una maestra y un sociólogo en el conurbano bonaerense. Buenos Aires, Katz, 2013.

BARANGER, Denis. Epistemología y metodología en la obra de Pierre Bourdieu. Buenos Aires, Prometeo, 2004.

BOURDIEU, Pierre. Cosas dichas. Barcelona, Gedisa,1988.

BOURDIEU, Pierre; CHAMBOREDON, Jean-Claude; PASSERON, Jean-Claude. EI oficio de sociólogo: presupuestos epistemológicos. Buenos Aires, Siglo XXI, 2002.

DI NAPOLI, Pablo; SZAPU, Ezequiel. Reflexiones sobre el cuerpo desde la teoría de los procesos civilizadores de Norbert Elias. En: KAPLAN, Carina V.; SARAT, Magda (Comp.), Educación y procesos de civilización. Miradas desde la obra de Norbert Elias. Buenos Aires, Editorial de la Facultad de FFyL- UBA, 2016, p. 183-205. Disponible en:

http://repositorio.filo.uba.ar/bitstream/handle/filodigital/2948/Educacion\%20y $\% 20$ procesos $\% 20$ de $\% 20$ civilizacion $\% 20$ interactivo.pdf?sequence=1\&isAllowed =y Acesso em: 13 mar. 2021.

ELIAS, Norbert. El proceso de la civilización. Investigaciones sociogenéticas y psicogenéticas. Madrid, Fondo de Cultura Económica, 1987.

ELIAS, Norbert. La sociedad de los individuos. Barcelona, Península, 1990.

ELIAS, Norbert. Sociología Fundamental. Barcelona, Gedisa, 2008. ELIAS, Norbert; SCOTSON, John L. Establecidos y marginados. Una investigación sociológica sobre problemas comunitarios. México, Fondo de Cultura Económica, 2016.

GLASER, Barney; STRAUSS, Anselm. The Discovery of Grounded Theory: Strategies for Qualitative Research (4. paperback printing). New Brunswick, Aldine, 2009.

GÓMEZ-GÓMEZ, Elba N. La investigación educativa: de lo hipotético deductivo a lo interpretativo. Sinéctica, (7). Tlaquepaque, Jalisco: ITESO, 1995.

GUTIÉRREZ, Alicia B. Las prácticas sociales: Una introducción a Pierre Bourdieu. Córdoba, Ferreyra Editor, 2005.

GUTIÉRREZ, José. El proceso de investigación cualitativo desde la investigación interpretativa y la investigación acción. En EISMAN, Leonor Buendía; BRAVO, 
María Pilar Colás. (Eds.) Modelos de análisis de la investigación educativa. Sevilla, Alfar, 1999, p. 65-79.

KAPLAN, Carina V. Talentos, dones e inteligencia: El fracaso escolar no es un destino. Buenos Aires, Ediciones Colihue, 2008.

KAPLAN, Carina V. Violencia escolar bajo sospecha. Buenos Aires, Miño y Dávila editores, 2009.

KAPLAN, Carina V. Mirada social, exclusión simbólica y auto-estigmatización. En KAPLAN, Carina V.; KROTSCH, Lucas; ORCE, Victoria Orce. Con ojos de joven. Relaciones entre desigualdad, violencia y condición juvenil. Buenos Aires, Editorial de la Facultad de FFyL- UBA, 2012, p. 15-78. Disponible en:

http://publicaciones.filo.uba.ar/sites/publicaciones.filo.uba.ar/files/Con\%200jo s\%20de\%20joven_interactivo_0.pdf Acesso em: 13 mar. 2021.

KAPLAN, Carina V. El miedo a morir joven. Meditaciones de los estudiantes sobre la condición humana. En KAPLAN, Carina. V. (dir.) Culturas estudiantiles: Sociología de los vínculos en la escuela. Buenos Aires, Argentina: Miño y Dávila editores, 2013.

KAPLAN, Carina V. El lenguaje es una piel. Género, violencia y procesos civilizatorios. En KAPLAN, Carina V. (Dir.). Género es más que una palabra. Educar sin etiquetas. Buenos Aires, Miño y Dávila editores, 2016, p. 211223.

KAPLAN, Carina V.; KROTSCH, Lucas F. La educación de las emociones: Una perspectiva desde Norbert Elias. En Revista Latinoamericana de Investigación Crítica, n. 5, v. 8, p. 119-134, 2018.

KAPLAN, Carina V.; SZAPU, Ezequiel. El racismo del cuerpo: procesos psicosociológicos de discriminación escolar. Pensamiento Psicológico, Colombia n. 17, v. 2, p. 107-119, 2019. Disponible en: https://revistas.javerianacali.edu.co/index.php/pensamientopsicologico/article/ view/1859/2828 Acesso em: 12 fev. 2021.

KAPLAN, Carina V.; SZAPU, Ezequiel. Conflictos, violencias y emociones en el ámbito educativo. México, CLACSO, Voces de la Educación, ENSV y Nosótrica Ediciones, 2020. Disponible en:

http://209.177.156.169/libreria_cm/archivos/pdf_1804.pdf Acesso em 25 mar. 2021.

KESSLER, Gabriel. Las consecuencias de la estigmatización territorial. Reflexiones a partir de un caso particular. En Espacios en Blanco, Serie indagaciones, n. 22, p. 165-197, 2012. 
LE BRETON, David. Rostros. Buenos Aires, Letra Viva, 2010.

MARRADI, Alberto; ARCHENTI, Nélida; PIOVANI, Juan I. Manual de

Metodología de las Ciencias Sociales. Buenos Aires, Siglo XXI, 2018.

PORTA, Luis; Silva, Miriam. La investigación cualitativa: el análisis de contenido en la investigación educativa. En Anuario Digital de

Investigación Educativa, n. 14, p. 1-18, 2003.

SIRVENT, María T. El proceso de investigación. Buenos Aires, Editorial de la Facultad de Filosofía y Letras - UBA, 2006.

VAN DIJK, Teun. Discurso racista. En PEROSANZ, Juan José Igartua; MÚÑIZ, Carlos (Eds.) Medios de comunicación y sociedad. Salamanca, Ediciones Universidad de Salamanca, 2007.

VASILACHIS DE GIALDINO, Irene. La investigación cualitativa. En GIALDINO, Irene Vasilachis. Estrategias de investigación cualitativa. Barcelona, Gedisa, 2006.

VERGARA MATTAR, Gabriela. Norbert Elías: El cuerpo en los entramados a la lógica de lo procesual. En Revista Argentina de Sociología, v. 8, n. 14, p. 15-34, 2010. Disponible en:

http://www.redalyc.org/articulo.oa?id=26922202002 Acesso em 22 mar. 2021.

YUNI, José A.; URBANO, Claudio M. Técnicas para investigar: recursos etodológicos para la preparación de proyectos de investigación.

Córdoba, Brujas, 2014.

Recebido em: 02 de março de 2021.

Aceito em: 04 de maio de 2021. Publicado em: 30 de junho de 2021. 